\title{
CÉSAR L. RAÑA DAFONTE, MEDIEVALISTA
}

\author{
Martín González Fernández \\ Universidad de Santiago de Compostela
}

Debo agradecer, de forma especial, a la Dirección de la Revista Española de la Filosofía Medieval, el honor que me hace al permitirme que redacte la semblanza de una persona muy querida para mí, y para toda la Universidad de Santiago de Compostela (USC), maestro, colega y amigo, el Dr. D. César L. Raña Dafonte, nuestro oficial y emblemático «historiador de la filosofía medieval», con motivo de su jubilación académica. No en vano, y pese a ésta, la USC le ha nombrado profesor ad honorem y, en tal condición, asesora al profesorado joven e imparte cursos de posgrado.

César ha contribuido, no sólo al florecimiento de estudios medievales en la Facultad de Filosofía de la USC y en Galicia, sino, al mismo tiempo, a la consolidación de dicho centro de estudios, del que es docente desde sus inicios. Nació en 1940 en la localidad de Deixebre, próxima a Santiago de Compostela y tan querida para él, donde su padre era maestro. La fidelidad a la memoria del padre tal vez haya marcado a la larga la vocación de enseñanza de este hijo, que lo perdió cuando todavía era un niño, pero cuya figura le ha sido recordada, día a día, desde su prematura pérdida al presente, por las generaciones de familias y alumnos agradecidos, del entorno de los concellos de Oroso y Ordes, que pasaron por las manos de D. Pedro Raña. Y tengo para mí que ser hijo de tal padre, más allá de sus muchos méritos académicos, intelectuales y de investigación, sigue siendo para él, junto al progreso de sus propios hijos, el mayor motivo de orgullo. En Deixebre, nos repite, es todavía hoy «César o do Maestro». Se formó, desde los 10 años hasta la adolescencia, en el Seminario Conciliar de Santiago. Siguió estudios de teología y filosofía, luego, en la Universidad de Salamanca, de la que guarda entrañables recuerdos (Vicente Muñoz Delgado o Guillermo Fraile fueron mentores y guías para él), al margen de una sólida formación científica. Allí se licenció, primero, en teología (1963) y filosofía (1965), en la pontificia, y de Filosofía y Letras (sección Filosofía) (1971), en la civil. Creada la Facultad de Filosofía de la USC, en 1974, su promotor, Carlos A. Baliñas Fernández, lo llama e incorpora al cuerpo docente. Se doctora en ella en 1977 con un estudio sobre Ángel Amor Ruibal. Su dedicación a la docencia de filosofía medieval ha marcado su destino académico.

Sus primeros trabajos versaron, como queda dicho, sobre Amor Ruibal, de quien no ha dejado de ocuparse ocasionalmente luego. Su estudio capital, fruto de su Tesis Doctoral, es La Concepción de la Divinidad en el pensamiento de Amor Ruibal (Santiago de Compostela: USC, 1977). En el año 2000, no hace tanto, se encargaba todavía de la edición crítica del volumen IV de su magna obra, Los Problemas Fundamentales de la Filosofía y del Dogma (Santiago de Compostela: Xunta de Galicia/ Servicio de Publicaciones, 2000). Además de recordar, en algún trabajo, a sus maestros en este campo («Carlos Baliñas y Ángel Amor Ruibal». En: La filosofía y sus márgenes. Homenaje al profesor Carlos A. Baliñas Fernández. Santiago de Compostela: USC, 1997, pp. 431-439, o «Vicente Muñoz Delgado y Ángel Amor 
Ruibal», Revista Española de Filosofía Medieval, 4 (1997), pp. 175-187), pronto han derivado sus trabajos hacia la interpretación de cuestiones medievales en este autor, marcando ya el paso definitivo al área de estudio en la que finalmente se ha especializado. Nos referimos a trabajos como: «Averroes según Amor Ruibal» (En: Averroes y los averroísmos. Zaragoza, Ibercaja, 1999, pp. 191-196), «La analogía según Ángel Amor Ruibal», Ágora (Papeles de Filosofía). Santiago de Compostela, n. 1 (1981), pp. 163-164, «Datos para una teodicea según Amor Ruibal», Compostellanum, vol. XXX, n. 1-2 (1985), pp. 141-165, «Un texto de Ángel Amor Ruibal», Azalea, núm. 3 (1990), pp. 179-222, «Análisis histórico-crítico del argumento anselmiano según Ángel Amor Ruibal», Revista Española de Filosofía Medieval, n. 2 (1995), p. 59-69, o «Crítica del entendimiento agente según Ángel Amor Ruibal», Revista Española de Filosofía Medieval, n. 9 (2002), p. 185-205. Es fuente viva de interés todavía para él.

Pronto, sin embargo, da el gran salto a la temática medieval, desde la historia de la filosofía y teología, en una triple vertiente, como divulgador, investigador y traductor. Sus excelentes conocimientos de teología, de la lengua latina e historia de la filosofía, su afinidad con la sensibilidad del humanismo de la Edad Media, que no oscura, se lo facilitan. Destaca pronto su pasión por la filosofía del siglo XII y sus autores más representativos. Su interés por el Renacimiento del siglo XII, se han saldado, hasta el momento, con dos libros y numerosos y valiosos artículos, así como la recuperación y versión al castellano de muchos textos de época, muy citados a veces, pero no siempre accesibles en español. Debemos destacar, en este sentido, sus monografías: Pedro Abelardo (1074-1142) (Madrid, Ed. del Orto, 1998) y Juan de Salisbury (1110/20-1180) (Madrid, Ed. del Orto, 1999). Los temas que más le han interesado y más ha investigado de esta época son: el humanismo, el descubrimiento del individuo, la enseñanza y su método, precedentes de la Ilustración y concepto de la Naturaleza. Su interés viene de muy atrás. Hay un trabajo suyo, pionero, muy alabado en su momento por Maurice de Gandillac, presente en el Simposio en que se expuso, que de algún modo avanza esta orientación de su labor investigadora, su ponencia «El humanismo del siglo XII y su proyección en el humanismo renacentista» (En: Filosofía y ciencia en el Renacimiento. Santiago de Compostela, USC, 1988, pp. 357-363). Luego han venido un gran número de estudios en los que se profundiza en esta dirección, a la vez que se abren perspectivas nuevas, algunas ya anotadas. Citaremos entre ellos: «La ética del Policraticus de Juan de Salisbury», en: Actas del II Congreso Nacional de Filosofía Medieval. Zaragoza, Ibercaja, 1996, pp. 439-447, «Sobre la tarea del escritor en el siglo XII (Pedro Abelardo, Juan de Salisbury)», en: De libros y libreros. Homenaje al librero Enrique Molist. A Coruña, Universidad de A Coruña, 1999, pp. 291-315, «Juan de Salisbury, un pedagogo 'moderno' en el siglo XII», en: A educación en perspectiva. Homenaxe ó Profesor Lisardo Doval Salgado. Santiago de Compostela, USC, 2000, pp. 731-751; «Lenguaje y filosofía en el siglo XII: Pedro Abelardo, Juan de Salisbury», en: Identidad y cultura. Reflexiones desde la filosofía. A Coruña, Universidad de A Coruña, 2001, pp. 281-295; «La vida cotidiana en el siglo XII y la reflexión ética de Pedro Abelardo», en: Pensar la vida cotidiana. Santiago de Compostela, USC, 2001, pp. 125-139; «La responsabilidad del escritor en la Edad Media: Pedro Abelardo y Juan de Salisbury», en: Hermenéutica y responsabilidad. Homenaje a Paul Ricoeur. Santiago de Compostela, USC, 2005, pp. 339-347; «Transición del platonismo al aristotelismo medieval: Juan de Salisbury», en: A tarefa de pensar. Homenaxe ao Profesor Carlos A. Baliñas Fernández. Noia, Sementeira, 2006, pp. 277-285, en el que se ofrecen elementos novedosos para interpretar el cambio de paradigmas filosóficos que se da en torno al siglo XII; «Los universales en Juan de Salisbury», Revista Española de Filosofía Medieval, n.. 6 (1999), pp. 185-194, donde toca un problema del que se ha ocupado con mayor extensión en otros estudios de divulgación; «La dimensión práctica de la filosofía según Juan de Salisbury», Revista Española de Filosofía Medieval, n. 10 (2003), pp. 219-227; «La libertad en Pedro Abelardo» Revista Española de Filosofía Medieval, n. 11 (2004), pp. 67-83; 
«En torno a la ética de Pedro Abelardo», Ágora (Papeles de filosofía), n. 3 (1983), pp. 203 211. Otros trabajos tienen un carácter más genérico, pero versan sobre este bloque temático. Citaremos los más recientes: «Ratio lucerna. La razón como guía en el siglo XII», Revista Española de Filosofía Medieval, n. 15 (2008), pp. 27-43; «Clavis aurea. Enseñanza y método en el siglo XII», Revista Española de Filosofía Medieval, n. 14 (2007), pp. 137-151; «Natura optima parens. La naturaleza en el siglo XII», Revista Española de Filosofía Medieval, n. 16 (2009), pp. $43-56$ (con selección de textos); «Magistrorum lectio. Una lección del siglo XII», Revista Española de Filosofía Medieval, n. 17 (2010), pp. 81-92 (incluye textos).

Un tema filosófico que siempre le ha interesado, y que finalmente ha encauzado también hacia el mundo medieval, es el de la teoría e historia de la ética. Ya hemos mencionado, sobre este aspecto, algunos trabajos puntuales, en tal o cual autor. Últimamente, en relación con el nacimiento del individuo en el siglo XII y el cambio de paradigma en ética, nos ha sorprendido con una fecunda e intensa labor de investigación en torno a los penitenciales, con estudios de carácter general, como su «Corrector et medicus. La ética altomedieval a la luz de los penitenciales», Revista Española de Filosofía Medieval, n. 13 (2006), pp. 159-165, y trabajos de traducción concretos, como el que luego mencionaremos sobre Alano de Lille, o su deliciosa «De vita non sancta en la Alta Edad Media», Revista Española de Filosofía Medieval, n. 12 (2005), pp. 191-204, que permite al lector contemplar en vivo el contraste respeto al nuevo enfoque o giro de la llamada «moral de la intención» de Pedro Abelardo.

Ya inmerso en el mundo filosófico medieval, se ha ocupado, al tiempo, de autores y temas de la época que encierran todavía candente actualidad, como la hermenéutica o el diálogo de culturas, además de temas transversales como el problema de los universales o las relaciones entre razón y fe o razón y autoridad. Entre esos otros autores, tan queridos para él, podemos mencionar a tres: Anselmo de Bec («La verdad según Anselmo de Bec», en: Actas del I Congreso Nacional de Filosofía Medieval Zaragoza, Ibercaja 1992, pp. 357-362, un estudio en profundidad sobre dicha problemática); Alano de Lille («Alano de Lille: los médicos del espíritu», en: Experiencia et sapientia. Estudios dedicados a la memoria de Ángel Álvarez. Gómez. Santiago de Compostela, USC, 2007, pp. 427-437, o «Maestro de Lille. Libro penitencial», introducción y edición crítica, Revista Española de Filosofía Medieval, n. 13 (2006), pp. 193-213, que se puede incluir ya en el apartado de traducciones, del que luego hablaremos) y, deuda obliga, Pedro Compostelano («Problemática en torno a la obra De consolatione rationis de Petrus Compostelanus», en Revista Española de Filosofía Medieval, n. 0 (1993), pp. 35-40; «Pedro Compostelano y el recto caminar», en: Filosofía del camino y camino de la filosofía. Santiago de Compostela, USC, 2003, pp. 179-193; «El combate entre el mundo y la razón, según Pedro Compostelano». Revista Española de Filosofía Medieval, n. 1 (1994), pp. 27-37. Finalmente, la voz «Pedro Compostelán (¿? séc. XIV)», en: Dicionario Enciclopédico do Pensamento Galego. Santiago de Compostela/ Vigo, Xerais/ Consello da Cultura Galega, 2008, pp. 74-80), figura de la tierra como el mencionado Amor Ruibal, entrada en la que ha revisado los mejores estudios dedicados a este autor (Blanco Soto, González-Haba, Casimiro Torres, entre otros), avanzando nuevas perspectivas de lectura. Algunos estudios están ligados a los Congresos nacionales e internacionales de filosofía medieval, escritos para la ocasión: «Ars interpretandi en Guía de Perplejos», en Maimónides y el pensamiento medieval. Córdoba, Universidad de Córdoba, 2007, pp. 293-301, o «De membris conspirantibus. Razón y Rebelión en el siglo XII», en: El pensamiento político en la Edad Media. Madrid: Fundación Areses, 2010,pp. 619-630. Otros recogen escenas de grupo: «Influencias filosóficas en la idea de Dios de los primeros teólogos cristianos», Agora (Papeles de filosofía), n. 5 (1985), pp. 89-100. Ya hemos indicado antes que él ve gérmenes, no sólo del Humanismo, sino incluso de la Ilustración, en algunos autores de la época medieval. Y ha destacado, en ellos, temas que guardan todavía importante vigencia. La educación y la nueva orientación de la ética, 
desde luego, así como la preocupación, más reflexiva y menos simbólica, en el estudio de la Naturaleza. Por mencionar algunos trabajos, en este sentido, citaríamos: «El diálogo entre culturas», en: Concordia y violencia: una reflexión filosófica para el mundo de hoy. Santiago de Compostela, USC, 2006, pp. 125-135; «La interpretación de textos en la Edad Media», en: Horizontes de la Hermenéutica. Santiago de Compostela, USC, 1998, pp. 291-315. De los temas que hemos llamado transversales, destacaríamos aquí especialmente dos trabajos importantes: «La frontera entre razón y autoridad en la Edad Media», en: Pensadores de fronteras. A Coruña: Universidade de A Coruña, 2003, pp. 83-97 y «Orixe e significado do problema dos universais no mundo medieval», Revista de Filosofía. Narón. A Coruña, n. 2 (1993), pp. 35-40. Su trabajo en el comité de dirección de la Sociedad Interuniversitaria de Filosofía, con sede en Santiago, de la que es miembro fundador y en donde participan profesores de las tres universidades gallegas, le ha permitido ampliar nuevos horizontes en la divulgación de los estudios de su especialidad y abrir nuevas puertas a la investigación, atrayendo a un público más general y menos especializado, pero siempre tan necesario en este campo.

Hemos hablado antes de traducciones. Nos ha dejado traslación limpia, pulcra, de pequeñas perlas de la historia de la filosofía medieval. No sólo ha incorporado gran número de textos a sus monografías mencionadas. Especialmente en la sección de documentos de la Revista Española de Filosofía Medieval, pero no sólo ahí, nos ha acercado importantes documentos a través su labor de edición crítica. Se ha mencionado, más atrás, el caso de la literatura de los penitenciales, educación y método, o su selección de textos sobre la filosofía de la Naturaleza del siglo XII. Debemos anotar, además, en este cómputo, su versión del «Poema sobre la conspiración de los miembros corporales (Carmen de membris corporantibus)» de Juan de Salisbury, Revista Española de Filosofía Medieval, n. 11 (2004), pp. 301-311; la traducción y edición crítica del «Prologus» del Sic et Non de Pedro Abelardo, Revista Española de Filosofía Medieval, n. 12 (2005), pp. 191-204; la traducción y edición crítica del opúsculo de Honorio de Autún (siglo XII) «De animae exsilio et patria, alias, De artibus (El exilio y la patria del alma, o Sobre las Artes)», Revista Española de Filosofía Medieval, n. 17 (2010), pp. 170-179; los textos de Hugo de San Víctor, otro de sus autores preferidos, recogida en «Un documento del siglo XII», en: Fidelidade a Terra. Homenaxe a Xosé Luis Barreiro Barreiro. Santiago de Compostela, USC, 2011, pp. 385-394. Lo mejor del medievalista César L. Raña Dafonte está todavía por llegar. Todos ansiamos, y más aquellos que especialmente nos sentimos ligados a la escuela que ha formado y deja en la USC, su definitivo libro sobre el pensamiento filosófico y renacimiento del siglo XII, y esperamos que éste vea pronto la luz.

Hemos dejado constancia, hasta aquí, de una vida - esta vez sí sancta, y paciente - dedicada al estudio, a la enseñanza y a la investigación. Pero aún quisiéramos destacar dos nuevos méritos de nuestro homenajeado, el uno académico y el otro personal. En cuanto al primero, decir tan sólo que César L. Raña Dafonte, desde su propio dominio de trabajo e investigación, el del mundo y la filosofía medieval, ha puesto a la USC en contacto con las grandes sociedades y publicaciones, nacionales e internacionales, de su especialidad (Sociedad Española de Filosofía Medieval, con sede en Zaragoza, Sociedad Internacional de Filosofía Medieval, con sede en Lovaina, Revista Española de Filosofía Medieval). Ha participado en todos los Congresos Nacionales y en algunos Internacionales de su disciplina, puestos en marcha por estas entidades, dando voz y brillo propio siempre en ellos a la USC. Muchas veces le he escuchado el lamento de, por razones de salud, no haber podido traer a nuestra hermosa ciudad, pórtico del Camino de Santiago y de sus peregrinaciones, y de la Cristiandad, alguno de estos eventos. Pero todo hombre tiene sus limitaciones y él ha sabido también aceptar las suyas. Tal vez, con el tiempo, quién sabe, se haga realidad este viejo sueño del maestro. Y al margen de su presencia individual en estas actividades y organismos, lo realmente importante es que ha conseguido colocar a la Facultad de Filosofía de la USC en la red de las principales institucio- 
nes y centros de estudio y divulgación de la filosofía medieval. Este es un mérito que ya nadie podrá quitarle y borrar de la memoria colectiva. El otro mérito es ya de índole humana. Tiene que ver con su carácter, enérgico por veces, pero ejemplarmente generoso siempre. Profesor muy querido en la USC, entre los alumnos, por sus dotes pedagógicas y su accesibilidad, no lo ha sido menos entre sus colegas: siempre ha estado ahí, nunca le ha fallado a nadie, tanto para solucionar una duda teórica como para echar una mano en un momento de apuro en el trabajo a alguno de sus compañeros, nunca ha dicho que no, siempre ha estado disponible, para orientar, dirigir, ayudar. Es el testigo que, tomado de su padre, está trasmitiendo ya, en compañía de Pili, su mujer, y de sus hijos, a su nieto Yago.

Martín González Fernández Universidad de Santiago de Compostela martin.gonzalez@usc.es 